\title{
Epidemiological and functional profile of patients diagnosed with multiple sclerosis in Manaus, Amazonas
}

\section{Perfil epidemiológico e funcional de pacientes com diagnóstico de esclerose múltipla em Manaus, Amazonas}

Luciana Moreira de Souza ${ }^{1}$, Edinangela Silva de Oliveira ${ }^{1}$, Nisi Alessandra de Carvalho Sousa ${ }^{1}$, Guilherme Peixoto Tinoco Arêas ${ }^{2}$, (I)Fernando Zanela da Silva Arêas ${ }^{3}$

\begin{abstract}
Multiple sclerosis (MS) is an immune-mediated, inflammatory disease characterized by repeated episodes of demyelization. Objective: The present study aimed to trace the epidemiological and functional profile of patients with Multiple Sclerosis treated at a Reference Hospital in Manaus-AM. Method: 80 charts were selected for screening and subsequent application of the Functional Independence Measure (MIF) scale. Results: 32 patients were included in the study, 23 females (74\%), whose mean age was $35( \pm 12)$ years, with a relationship between females and males of 2.5. The mean diagnostic time for men was 7.8 years and for women of 5.3 years. The mean score on the Total MIF scale was 110.9 ( \pm 17.5 ). Conclusion: Epidemiological characteristics are in line with most similar studies, but lack further studies aimed at assessing the functionality of individuals with MS.
\end{abstract}

Keywords: Multiple Sclerosis, Medical Records, Epidemiologic Studies

\section{RESUMO}

A esclerose múltipla (EM) é uma doença imuno-mediada, inflamatória, caracterizada por repetidos episódios de desmielinização. Objetivo: Traçar o perfil epidemiológico e funcional dos pacientes com Esclerose Múltipla atendidos em um Hospital de Referência de Manaus-AM. Método: Foram selecionados 80 prontuários para triagem e posterior aplicação da escala de Medida de Independência Funcional (MIF). Resultado: Foram incluídos no estudo 32 pacientes, 23 do sexo feminino (74\%) cuja média de idade era de 35 ( \pm 12 ) anos verificando uma relação entre mulheres e homens de 2.5. O tempo de diagnóstico médio para os homens foi de 7.8 anos e para as mulheres de 5,3 anos. A média do escore na escala de MIF Total foi de $110,9( \pm 17,5)$. Conclusão: As características epidemiológicas estão em consonância com a maioria dos estudos semelhantes, mas carecem de mais estudos voltados para a avaliação da funcionalidade de indivíduos com EM.

Palavras-chave: Esclerose Múltipla, Registros Médicos, Estudos Epidemiológicos

Submitted: 08 May 2019

Approved: 20 May 2019

\section{How to cite}

Souza LM, Oliveira ES, Sousa NAC, Arêas GPT, Arêas FZS. Epidemiological and functional profile of patients diagnosed with multiple sclerosis in Manaus, Amazonas. Acta Fisiatr. 2018;25(4):174-178.

DOI: 10.11606/issn.2317-0190.v25i4a163863

\footnotetext{
Mailing address:

Fernando Zanela da Silva Arêas

E-mail: fernandozanela@hotmail.com

1Physical Therapy Departament, Universidade ${ }^{2}$ Virtual University Institute, Universidade Federal do Ceará - UFC

${ }^{3}$ Instituto Federal do Rio de Janeiro - IFRJ
}

\section{(c) (i) (9)}




\section{INTRODUCTION}

Multiple sclerosis (MS) is an autoimmune, inflammatory, demyelinating and chronic disease that affects the central nervous system (CNS; It is more common in young adults and has an unknown etiology. Given the differences in prevalence rates among populations, the most accepted pathogenic hypothesis presumes that the development of MS is influenced by an interaction among factors related to genetics, infectious agents, and environment. ${ }^{1-4}$ The illness is characterized by demyelination episodes that lead to multiform clinical manifestations, which may be disabling, and functional deficits resulting from damage to parts of the neuraxis. 5,6

The incidence and prevalence of MS vary considerably around the world, presenting a significant relationship with ethnicity and geographical area. ${ }^{7,8}$ More recent studies have suggested that there are several regions in Brazil and Latin America where there are mixedrace populations (European, African and Indian) that have developed over many generations.

As a consequence, these areas show peculiar population-shaping characteristics and important ethnic differences, which lead to distinct regional prevalence's of MS. A recent review defined five regional prevalence levels according to the number of affected people per 100,000 inhabitants: very low for 0 to 13 ; low for 13 to 38 ; intermediate for 38 to 70 ; high for 70 to 170 ; and very high for 170 to 35. 09,10

In Brazil, the highest prevalence's are reported in the South and Southeast regions, which suggests the existence of a South - North gradient. Even with this difference, the country is considered to have low prevalence of MS, with an average number of 15 affected people per 100,000 inhabitants. ${ }^{11,12}$

Because of diversity of symptoms and physiopathological processes, MS can vary in itssymptomatic presentation and follow an unpredictable, complex and heterogeneous clinical evolution..$^{13,14}$

Based on the decision of experts from the National Multiple Sclerosis Society in 1999, and according to clinical criteria characterized by progression or outbreak occurrence, the disease can be classified into several forms: relapsing-remitting (RRMS), primary progressive (PPMS), secondary progressive (SPMS) and progressiverelapsing (PRMS), as well as being categorized as benign or malignant. ${ }^{15}$ RRMS is the most common, and is characterized by clearly defined exacerbations, with complete recovery or permanent consequences and residual deficits. The other three types - PPMS, SPMS and PRMS - are marked by periods of progression of the disease. ${ }^{16-18}$

It is known that, after an injury to the CNS, many symptoms may imply the development of long-term consequences that can compromise the independent execution of functional activities; however, patients with the same disease and similar impairments may show different disabilities. ${ }^{19}$ The number of outbreaks, the time of evolution of the disease, the type of pyramidal impairments, and the presence of cerebellar or motor manifestations in the beginning of the condition are the main factors related to functional incapacity. 20 Because of the variety of symptoms in MS, several assessment scales have been created to evaluate those who are affected.

Kurtzke's Expanded Disability Status Scale (EDSS) is the one that is best known and most used in clinical trials on MS, although the literature indicates that there are some limitations to this tool that require it to be complemented by the addition of functional scales. ${ }^{21,22}$

Rehabilitation programs currently use the Functional Independence Measure (FIM) as a source of information in order to determine limitations, plan the best therapeutic approaches, and follow patients' evolution. ${ }^{23,24}$

The FIM is one of the most common scales used to determine functional level in neurological patients. It has been applied to different diseases of the nervous system and in many age groups, and has been shown to be valid, sensitive and reliable.

\section{OBJECTIVE}

The aim of the present study was to describe the epidemiological and functional profile of patients diagnosed with MS who were admitted to the Demyelinating Diseases Service of Getúlio Vargas University Hospital, in Manaus, Amazonas. ${ }^{14}$

\section{METHODS}

This was a retrospective, cross-sectional and descriptive prospective study carried out with patients previously diagnosed with MS, utilizing data collected at the Demyelinating Diseases Service at Getúlio Vargas University Hospital, in Manaus, Amazonas.

The participants were informed of the objectives and procedures of the study, and signed free and informed consent forms. This study was approved by the Research Ethics Committee of Federal University of Amazonas, under approval certificate CAE 61619716.8.0000.5020, and approval report 1.815.182.

Data collection occurred in two stages, without restrictions as for age, site or extent of the lesion, origin and gender, and with participants who met the following inclusion criteria: having a definite diagnosis of MS, being within reach to be found and contacted, and being able to answer the FIM questionnaire.

The first stage consisted of analyzing reports on patients admitted and diagnosed with MS between January 2010 and December 2015, with no restrictions regarding age, origin, gender, location or extension of the injury. In the second stage, this information was entered into forms with patients' personal and clinical data.

Patients were then identified, located, and contacted by phone in order to apply a functional assessment. The tool used to evaluate the disability of patients with restrictions was the Functional Independence Measure. The patients had to be able to answer simple questions or be accompanied by an acquaintance during the application of the questionnaire.

Eighty medical records from patients identified during the first stage were analyzed; 48 were discarded, 20 because they did not have a definitive MS diagnosis and 28 because it was not possible to locate them to apply the FIM. Consequently, the sample for the study consisted of 32 patients who met the inclusion criteria.

The functional profile analysis was carried out by the FIM, which is a self-administered instrument to evaluate performance of motor and cognitive/social skills, and the assistance needed to carry out activities.

The FIM includes 18 categories, each of which receives a score related to level of dependence: a score of 1 indicates total dependence and a score of 7 indicates total independence. The total score ranges from 18 to 126 , and the lower the score, the more dependent the patient.

The categories are grouped into six dimensions: 1) self-care (feeding, personal hygiene, bathing, dress upper half, dress lower half, use of the toilet); 2) sphincter control (control of urination and defecation); 3) transfers (bed, chair, wheelchair, toilet, bathroom, shower); 4) locomotion (gaits, wheelchair, stairs); 5) communication (understanding, expression); and 6) social cognition (social interaction, problem solving, memory). ${ }^{24}$

In the present study, only the total FIM score and the mobility (minimum of 3 and maximum of 21) and locomotion (minimum of 2 and maximum of 14) domains were assessed. An individual with no deficiencies reaches a score of 126 , and a person showing total dependence gets a score of $18 .{ }^{25,26}$

The data was expressed as average \pm standard deviation. Initially, the Shapiro-Wilk normality test was used. The Student's unpaired $t$ test was applied to analyze the difference between the normal means.

The difference between several means was assessed through analysis of variance (ANOVA) and a post hoc Bonferroni test. The significance level was set at $p<0.05$. 


\section{RESULTS}

Among the 32 patients included in the study, 29 were from Manaus and 3 lived in the countryside of the state of Amazonas. Twenty-three (74\%) were females, with an average age of $35 \pm 12$ years, and $9(26 \%)$ were males, with an average age of $35 \pm 11$ years, a proportion of 2.5 women for each man.

The patients' ages varied from 12 to 60 years old; $46.8 \%$ were between 31 and 40 years old. The average time since diagnosis was 7.8 years for men and 5.3 years for women. The patients' characteristics, shown in Table 1, did not present statistically significant differences; however, women were predominant in the sample.

Table 1. Epidemiological characteristics of patients diagnosed with MS at the Demyelinating Diseases Service in Manaus, Amazonas, Brazil, between January 2010 and December 2015

\begin{tabular}{lcc}
\hline \multicolumn{1}{c}{ Variables } & $\mathbf{N = 3 2}$ \\
& Men $(\mathbf{n = 0 9 )}$ & Women $(\mathbf{n = 2 3})$ \\
\hline Proportion (\%) & $26 \%$ & $74 \%$ \\
Age group (years \pm SD) & $35 \pm 11$ & $35 \pm 12$ \\
Time since diagnosis (years) & 7.8 & 5.3 \\
\hline$S D=$ standard deviation & &
\end{tabular}

$S D=$ standard deviation

Table 2 exhibits comparative data with the average total FIM, mobility and locomotion scores and their standard deviation for gender, age group and time since diagnosis. Women presented higher average scores, and these values were statistically significant $(p=0.03)$ for both the total FIM score $(115 \pm 7)$ and the mobility score $(20 \pm 1)$.

This showed that women had lower functional dependence when compared to men, whose average total FIM score was $100 \pm 29$, with a score of $17 \pm 6$ in the mobility domain.

Table 2. Mean values for scores on the FIM. Total score and scores for mobility and locomotion domains for patients diagnosed with MS at the Demyelinating Diseases Service in Manaus, Amazonas, Brazil, between January 2010 and December 2015

\begin{tabular}{lccc}
\hline \multicolumn{1}{c}{ Variables } & $\begin{array}{c}\text { FIM } \\
\text { (total) }\end{array}$ & $\begin{array}{c}\text { FIM } \\
\text { (mobility) }\end{array}$ & $\begin{array}{c}\text { FIM } \\
\text { (locomotion) }\end{array}$ \\
\hline Sample $(n=32)$ & $110.9 \pm 17.5$ & Score + SD & \\
Gender & & & \\
Female $(n=23)$ & $115 \pm 7^{*}$ & $20 \pm 1 *$ & $13 \pm 1$ \\
Male $(n=9)$ & $100 \pm 29$ & $17 \pm 6$ & $11 \pm 4$ \\
Age group (years) & & & \\
Less than $30(n=09)$ & $110 \pm 17$ & $19 \pm 2$ & $13 \pm 2$ \\
31 to 40 ( $n=15)$ & $115 \pm 7$ & $20 \pm 0.7$ & $13 \pm 0.8$ \\
More than 40 (n=08) & $103 \pm 28$ & $18 \pm 6$ & $11 \pm 4$ \\
Time since diagnosis (years) & & & \\
1 to 4 ( $n=11)$ & $115 \pm 8$ & $20 \pm 0.9$ & $13 \pm 1$ \\
5 to $9(n=16)$ & $112 \pm 12$ & $20 \pm 2$ & $13 \pm 1$ \\
10 or more $(n=05)$ & $94 \pm 33$ & $16 \pm 7$ & $10 \pm 5$ \\
\hline * $p=0.03: S D=$ standard deviation & & &
\end{tabular}

Regarding the functional profile of the sample, the comparison of average total FIM scores among the variables revealed that most of these patients got scores near the maximum value (126 points); it was observed that these people had the capacity to perform their activities and needed little assistance.

There was no statistical significance for age group and time since diagnosis among the patients in any of the three FIM categories, but the lowest average values were found for patients aged more than 40 years old with a time since diagnosis of 10 years or more. This result points to the hypothesis that older patients with more time since diagnosis present a functionally more dependent profile when compared to people who do not present these characteristics.

\section{DISCUSSION}

In the North region of Brazil, including the city of Manaus, there are few studies focused on the clinical and epidemiological aspects of MS, let alone its prevalence and incidence. The present study provides information at one point in time for a specialized public service in Manaus that is considered a reference center for demyelinating diseases. As such, it provides a situational diagnosis of the epidemiology and functionality of people with MS.

Analysis of the epidemiological data shows a predominance of MS cases in females (74\%). This is in accordance with an experiment carried out in Uberaba, Minas Gerais by Ribeiro et al. ${ }^{27}$ who observed a predominance of women $(71.4 \%)$ in a sample similar in number (35 patients) to the one described in the present paper (35 patients).

Ferreira et al. ${ }^{12}$ Negreiros et al. ${ }^{28}$ and Cardoso et al. ${ }^{6}$ also obtained comparable results regarding gender predominance in cities in Pernambuco, Paraíba and São Paulo, respectively, confirming a higher propensity of women for developing MS. As for average age, the findings of the present study were consistent with most of the literature for both genders, corroborating the fact that MS affects mainly young adults.

Several instruments have been used to assess functional skills in patients with MS. Most studies describe the use of Kurtzke's Expanded Disability Status Scale (EDSS); however, because of its limitations, researchers tend to complement it with other functional scales. ${ }^{21,22}$ In the present study, the authors opted for the FIM instrument, which was developed as an assessment tool that can be used to measure the current functional level of patients. The drawback of its use is the difficulty of comparing its results with the findings of other studies.

To evaluate the functionality of patients, cutoff values for analysis of the total FIM scores were based on those used by Riberto et al. ${ }^{24}$ The following score intervals were chosen: 18 , complete dependence (total assistance); $19-60$, modified dependence (assistance of up to $50 \%$ in an activity); $61-103$, modified dependence (assistance of up to $25 \%$ in an activity); $104-126$, complete/modified independence. Hence, the lower the score, the higher the level of dependence.

The average total FIM score of $110.9 \pm 17.5$ showed a population characterized by complete/modified independence. Gender analysis, however, showed that female patients were mainly responsible for this result, with an average score of $115 \pm 7$; the male patients obtained an average score of $100 \pm 29$, which puts them at the level of modified dependence, needing up to $25 \%$ of assistance to complete an activity.

According to a study by Tremlett et al. ${ }^{17}$ in which the female participants showed a $30 \%$ lower risk of obtaining low scores in the EDSS scale, even although MS is more frequent in females, the worst prognoses of long-term incapacity were made for affected men. Nevertheless, this conclusion still needs deeper analysis, and new investigations focused on the functional state of patients need to be carried out. $14,23,24$

Regarding age group, patients more than 40 years old and with a time since diagnosis of more than ten years were categorized as requiring modified dependence and assistance of $25 \%$, unlike younger patients, who showed complete/modified independence, as well as those diagnosed between 1 and 4 years ago.

This finding suggests that age and time since diagnosis may interfere with clinical progression for these patients, particularly level of dependence. However, in order to confirm this hypothesis, other clinical factors of the disease need to be investigated.

A systematic review by Vasconcelos et al. ${ }^{29}$ shows that there are prognostic aspects associated with demographic and clinical characteristics directly related to the progression of $\mathrm{MS}$, and consequently, to functional performance, that are not limited to the data collected in the present study. 
The prognostic factors that are more commonly addressed and associated with clinical progression are, in addition to gender: the outbreak frequency in the first years of the disease; the residual deficit after the initial outbreak; the time interval between the first two outbreaks; and ethnicity.

This set of information is paramount for accurately characterizing samples, given that MS is an illness with fluctuating clinical features and has stability phases that determine the impairment of patients' capacities.

This applies to recent research about MS in Brazil: Several studies have described the sociodemographic and epidemiological characteristics of patients with MS, but lack assessment of their functionality in addition to their clinical condition. That is why the analyses in the present study are based more on clinical reasoning in comparison with other research.

As for clinical and demographic information, the present study revealed a few limitations during data collection. Nonetheless, it is hoped that it will contribute to unveiling the reality of MS in Manaus, Amazonas and the North region, so that the disease can be better mapped through incidence and prevalence studies in the near future.

Also, since the study is based on data from a single public service, it does not reflect the situation of the state or the region. However, the objective of the present investigation was to describe the epidemiological and functional features of patients with MS from Manaus, where there is a center of reference for the treatment of this condition that admits patients from the entire state.

Hence, it is hoped that the study will encourage researchers to carry out more epidemiological and clinical studies on MS that allow assessment of the functional state of patients in other regions of the country, especially in states in the region, an area that lacks investigation of this topic.

\section{ACKNOWLEDGMENTS}

The authors would like to express their gratitude to everyone who provided assistance in this research. Special thanks go to the staff of the Demyelinating Diseases Service for providing a favorable environment during data collection.

\section{REFERENCES}

1. Compston A. Esclerosis multiple. In: Brostoff J, Scadding GK, Male DK, Roitt IM (eds). Inmunología clínica. London: Gower Med; 1994:9.2-9.7.

2. Hillert J. Human leukocyte antigen studies in multiple sclerosis. Ann Neurol. 1994;36 Suppl:S15-7. DOI: https://doi.org/10.1002/ana.410360706

3. Poser CM, Brinar VV. The accuracy of prevalence rates of multiple sclerosis: a critical review. Neuroepidemiology. 2007;29(3-4):1505. DOI: https://doi.org/10.1159/000111576

4. Noseworthy JH, Lucchinetti C, Rodriguez M, Weinshenker BG. Multiple sclerosis. N Engl J Med. 2000;343(13):938-52. DOI: https://doi.org/10.1056/NEJM200009283431307

5. Kurtzke JF, Beebe GW, Nagler B, Auth TL, Kurland LT, Nefzger MD. Studies on the natural history of multiple sclerosis. 6. Clinical and laboratory findings at first diagnosis. Acta Neurol Scand. 1972;48(1):19-46. DOI: https://doi.org/10.1111/j.16000404.1972.tb07525.x

6. Cardoso E, Fukuda T, Pereira J, Seixas J, Miranda R, Rodrigues B, et al. Clinical and epidemiological profile of multiple sclerosis in a reference center in the State of Bahia, Brazil. Arq Neuropsiquiatr. 2006;64(3B):727-30. DOI: https://doi.org/10.1590/s0004$282 \times 2006000500005$

7. Cristiano E, Rojas J, Romano M, Frider N, Machnicki G, Giunta D, et al. The epidemiology of multiple sclerosis in Latin America and the Caribbean: a systematic review. Mult Scler. 2013;19(7):844-54. DOI: https://doi.org/10.1177/1352458512462918
8. Grzesiuk AK. Características clínicas e epidemiológicas de 20 pacientes portadores de esclerose múltipla acompanhados em Cuiabá - Mato Grosso. Arq Neuropsiquiatr. 2006;64(3A):635-8. DOI: http://dx.doi.org/10.1590/S0004-282X2006000400022

9. Brum DG, Barreira AA, Louzada-Junior $P$, Mendes-Junior $C T$, Donadi EA. Association of the HLA-DRB1*15 allele group and the DRB1*1501 and DRB1*1503 alleles with multiple sclerosis in White and Mulatto samples from Brazil. J Neuroimmunol. 2007;189(1-2):118-24. https://doi.org/10.1016/j.jneuroim.2007.06.009

10. Risco J, Maldonado H, Luna L, Osada J, Ruiz P, Juarez A, et al. Latitudinal prevalence gradient of multiple sclerosis in Latin America. Mult Scler. 2011;17(9):1055-9. DOI: https://doi.org/10.1177/1352458511405562

11. Brasil. Ministério da Saúde. Portaria n. 391, de 5 de maio de 2015. Aprova o protocolo clínico e diretrizes terapêuticas da esclerose múltipla. Diário Oficial da República Federativa do Brasil, Brasília (DF); 2015 Maio 06, Seção 1: 40.

12. Ferreira ML, Machado MI, Vilela ML, Guedes MJ, Ataíde L Jr, Santos S, et al. Epidemiologia de 118 casos de esclerose múltipla com seguimento de 15 anos no centro de referência do Hospital da Restauração de Pernambuco. Arq Neuropsiquiatr. 2004;62(4):1027-32. DOI: http://dx.doi.org/10.1590/S0004$282 \times 2004000600018$

13. Nessler S, Brück W. Advances in multiple sclerosis research in 2009. J Neurol. 2010;257(9):1590-3. DOI: https://doi.org/10.1007/s00415-010-5689-y

14. Kantarci $\mathrm{OH}$, Pirko I, Rodriguez M. Novel immunomodulatory approaches for the management of multiple sclerosis. Clin Pharmacol Ther. 2014;95(1):32-44. DOI: https://doi.org/10.1038/clpt.2013.196

15. Lublin FD, Reingold SC. Defining the clinical course of multiple sclerosis: results of an international survey. National Multiple Sclerosis Society (USA) Advisory Committee on Clinical Trials of New Agents in Multiple Sclerosis. Neurology. 1996;46(4):907-11. DOI: https://doi.org/10.1212/wnl.46.4.907

16. Scalfari A, Neuhaus A, Daumer M, Muraro PA, Ebers GC. Onset of secondary progressive phase and long-term evolution of multiple sclerosis. J Neurol Neurosurg Psychiatry. 2014;85(1):67-75. DOI: https://doi.org/10.1136/jnnp-2012-304333

17. Tremlett H, Yousefi M, Devonshire V, Rieckmann P, Zhao Y; UBC Neurologists. Impact of multiple sclerosis relapses on progression diminishes with time. Neurology. 2009;73(20):1616-23. DOI: https://doi.org/10.1212/WNL.0b013e3181c1e44f

18. Hammond SR, McLeod JG, Macaskill P, English DR. Multiple sclerosis in Australia: prognostic factors. J Clin Neurosci. 2000;7(1):16-9. DOI: https://doi.org/10.1054/jocn.1998.0107

19. Verheyden G, Nieuwboer A, De Wit L, Thijs V, Dobbelaere J, Devos $\mathrm{H}$, et al. Time course of trunk, arm, leg, and functional recovery after ischemic stroke. Neurorehabil Neural Repair. 2008;22(2):173-9. DOI: https://doi.org/10.1177/1545968307305456

20. Oliveira EML, Annes M, Oliveira ASB, Gabbai AA. Esclerose múltipla: estudo clínico de 50 pacientes acompanhados no Ambulatório de Neurologia UNIFESP-EPM. Arq Neuropsiquiatr. 1999;57(1):51-5. DOI: http://dx.doi.org/10.1590/S0004282X1999000100010

21. Filippi M, Rocca MA. Multiple sclerosis: monitoring long-term treatments in multiple sclerosis. Nat Rev Neurol. 2010;6(8):421-2. DOI: https://doi.org/10.1038/nrneurol.2010.88

22. Hobart JC, Riazi A, Lamping DL, Fitzpatrick R, Thompson AJ. Measuring the impact of MS on walking ability: the 12-Item MS Walking Scale (MSWS-12). Neurology. 2003;60(1):31-6. DOI: https://doi.org/10.1212/wnl.60.1.31

23. Hsueh IP, Lin JH, Jeng JS, Hsieh CL. Comparison of the psychometric characteristics of the functional independence measure, 5 item Barthel index, and 10 item Barthel index in patients with stroke. J Neurol Neurosurg Psychiatry. 2002;73(2):188-90. DOI: https://doi.org/10.1136/jnnp.73.2.188 
24. Riberto M, Miyazaki MH, Jucá SSH, Sakamoto H, Pinto PPN Battistella LR. Validação da Versão Brasileira da Medida de Independência Funcional. Acta Fisiatr. 2004;11(2):72-6. DOI: https://doi.org/10.5935/0104-7795.20040003

25. Silva GA, Schoeller SD, Gelbcke FL, Carvalho ZMA, Silva EMJP. Avaliação funcional de pessoas com lesão medular: utilização da Escala de Independência Funcional - MIF. Texto Contexto Enferm. 2012;21(4):929-36. DOI: http://dx.doi.org/10.1590/S010407072012000400025

26. Pompeu SMAA, Moral CD, Pompeu JE, Yumi E. Perfil funcional dos pacientes atendidos no setor de fisioterapia neurológica do Promove São Camilo. Mundo Saúde: 2010; 34(2): 218-24.

27. Ribeiro SBF, Maia DF, Ribeiro JB, Cardoso FAG, Silva C. Clinical and epidemiological profile of patients with multiple sclerosis in Uberaba, Minas Gerais, Brazil. Arq Neuropsiquiatr 2011; 69(2A):184-7. DOI: http://dx.doi.org/10.1590/S0004$282 \times 2011000200008$
28. Negreiros AA, Sousa-Munõz RL, Oliveira BE, Nóbrega PV, Monteiro LL. Perfil clínico-epidemiológico de pacientes com diagnóstico de esclerose múltipla na cidade de João Pessoa, Paraíba, Brasil. Arq Neuropsiquiatr. 2015;73(9):741-5. http://dx.doi.org/10.1590/0004-282X20150111

29. Vasconcelos CCF, Damasceno A, Diniz DS, Figueira FFA. Critérios de progressão e falência terapêutica na Esclerose Múltipla. In: Frota ERC, Mendes MF, Vasconcelos CCF. Recomendações no tratamento da esclerose múltipla e neuromielite óptica. 2 ed. São Paulo: Omnifarma; 2016. p.185-216. 